\title{
Ex Ante Desire And Post Hoc Satisfaction ${ }^{1}$
}

Seven years, My lord have now past since I waited in your outward Rooms or was repulsed from your Door, during which time I have been pushing on my work through difficulties of which it is useless to complain, and have brought it at last to the verge of Publication without one Act of assistance, one word of encouragement, or one smile of favour...The notice which you have been pleased to take of my Labours, had it been early, had been kind; but it has been delayed till I am indifferent and cannot enjoy it, till I am solitary and cannot impart it, till I am known, and do not want it.

\section{Dr. Johnson to Lord Chesterfield}

L. W. Sumner argues that the informed desire satisfaction account of welfare is unsatisfactory because, since desires precede the states of affairs that satisfy them, satisfying desires may fail to satisfy their agents. ${ }^{2}$

I argue that the temporal gap between our desires and the states of affairs that satisfy them poses no special problem for the desire theory. Even if getting what we want fails to satisfy us, we are ceteris paribus better off for having got it.

\section{DESIRES FOR STATES THAT AREN'T LIKE ANYTHING FOR US}

According to desire satisfaction accounts of welfare, a state of affairs is good for a person to the extent that it satisfies her [informed, rationally considered] desires. The rationale for rejecting hedonistic accounts of wellbeing in favor of desire theories is the intuition that states of affairs that aren't "like" anything for us can harm and benefit us. Many of us would hesitate to jump onto Nozick's Experience Machine because we believe that living in a fool's paradise is not a good thing. Life on the Experience 
Machine may be better than a life of palpable misery but it is not so good as a life of genuine activity and achievement, we believe, because we desire things other than feely psychological states and, intuitively, getting those things contributes to our wellbeing.

On the desire satisfaction account, feely psychological states also contribute to our wellbeing to the extent that we want them. Most of us want the knowledge that we have achieved our goals and the pleasant phenomenal state that goes along with that as well as the fact of achievement. Good feels, even without achievement, are good to the extent that we desire them and achievement without good feels is good insofar as we desire it, but good feels together with achievement are best of all. A minority of subjects aver that they would plug into the Experience Machine but we cannot conclude that this is an expression of their hedonistic intuitions: they may just rank good feels very highly in their preference orderings and be prepared to incur substantial opportunity costs to get them.

The desire theorist in any case holds that states of affairs that do not include any phenomenal component, including those that are wholly extrinsic to us, can benefit us. We can desire any possible state of affairs, and perhaps even some logically impossible ones, including the admiration of people we do not know and a place in history after our deaths. According to the desire theorist the satisfaction of such desires benefits us.

The desire theorist's intuition that states of affairs that make no difference to our experience can harm or benefit us is not universal. Sumner however suggests that even if we grant the desire theorist's fundamental assumption that they can make a difference to our well-being, the prospective character of desire, which opens a temporal gap between desires and the states of affairs that satisfy them, undermines the account. States of affairs 
that satisfy my desires may not satisfy me. (1) Getting what I wanted may turn out not to be like what I thought it would be like for me so that even though my desire is satisfied I am disappointed. (2) Worse still, my tastes, preferences and goals may change so that by the time I get what I wanted I might wish that things were otherwise. ${ }^{3}$ (3) Worst of all, my desire may come to be satisfied only after I am dead and not around to get any satisfaction out of it at all. ${ }^{4}$ These cases are putative counterexamples to the desire theory, which identifies welfare with desire satisfaction.

Prima facie the difficulties posed by the prospective character of desire are a linguistic artifact. Even if we cannot desire things we have or states of affairs that obtain, we can prefer them to other alternatives. Nevertheless, even if preference is not necessarily prospective, some preferences are and in a range of cases the satisfaction our preferences does not satisfy us, either because the objects of our preferences turn out to be disappointing when we get them or because our tastes have changed in the interim. So these putative counterexamples to the desire theory pose difficulties even if the account is formulated in terms of preferences: what are we to say about the satisfaction of preferences that we no longer have?

I argue that even if the satisfaction of our preferences does not satisfy us or leave us on net better off, it does benefit us. And this is all the desire theorist needs. Our inclination to believe that we do not benefit in these cases comes from the residual hedonist intuition that no state of affairs can benefit us unless it involves a feely psychological component. If we reject this assumption, as desire theorists must, the temporal gap between desires and their satisfaction poses no special problem for the desire theory. 


\section{Putative Counterexamples to The Desire Theory}

\section{Disappointment}

Even where we are adequately informed, duly deliberative and, by any reasonable account, desire that a given state of affairs obtain at a future time, we may still be disappointed when we discover what that state of affairs is like. When I desire $S$, I anticipate that $S$ will satisfy me. But I can be mistaken: "Between the idea and the reality...Falls the Shadow" and it lodges in the temporal gap between my desire and the state of affairs that satisfies it.

The obvious move is to close the gap by stipulating that my desire for a state, $S$, does not count as informed unless I correctly anticipate what $S$ will be like for me and know that I will find $S$ satisfying when I get it. Sumner however suggests that to close the gap by including knowledge about what the desired state of affairs will be like for us undermines the fundamental motivation of the desire theory:

The gap could be closed by stipulating that a desire does not count as informedand thus its satisfaction does not count as making me better off - whenever the desired state of affairs turns out upon later experience to be disappointing or unrewarding. However, to take this step would be to confirm the desire theorist's suspicion that, once our experience of states of the world is admitted as relevant, then whether or not these states satisfy antecedent desires on our part is on the way to becoming irrelevant. For it would be tantamount to conceding that what matters so far as our well-being is concerned, it is our satisfaction and not merely the satisfaction of our desires." 
The thought here is that including prior knowledge of what the objects of our desires will be like for us implicitly builds in an experience requirement for well-being: a desired state of affairs contributes to our well-being only if our experience of it does not turn out to be disappointing. Moreover having granted this much, Sumner suggests, it is hard to see why the character of our experience should not be sufficient as well as necessary for its contribution to our well-being.

Suppose I and my duplicate-at- $\mathrm{t}_{2}$ are both enjoying $S$ at $\mathrm{t}_{2}$ but that while I desired $S$ at $\mathrm{t}_{1}$ my duplicate did not: she had no idea in advance just how nice $S$ would be. As Sumner suggests however pleasant surprises benefit us: intuitively, all other things being equal, we're equally well off. Events that occur at other times might make a difference: I may have unlimited access to $S$ in the future while my duplicate is doomed to an $S$-less future and is worse off for having tasted it but it is not clear that that makes her worse off at $t_{2}$. In any case, past history, in particular whether or not we desired $S$ at $\mathrm{t}_{1}$ does not seem to make any difference. The desire theorist can certainly stipulate that $S$ doesn't count as benefiting my duplicate in virtue of the absence of any earlier desire for $S$ without any logical impropriety but this move seems at best ad hoc.

I suggest however while the phenomenal character of $S$ contributes to my wellbeing at $t_{2}$ it does so precisely because it is an object of my desire. I did not just want to get $S$. I also wanted to get a good feel out of it. Most of us have a standing desire to get good feels and we can assume that my duplicate, who was not born yesterday or created instantaneously for the sake of the thought experiment, had that standing desire as well. When we enjoy $S$ both of us benefit from the phenomenal state we get from $S$. Arguably 
however I am better off than my duplicate because I, in addition, satisfy the desire to get $S$ as such.

I have a special interest in the history of late antiquity in the eastern Mediterranean and one of my life's ambitions is to see Hagia Sophia. I travel with a friend who has never particularly wanted to go there. Nevertheless, both of us are equally thrilled by the architecture, ornament and atmosphere of the place. Still, it seems to me that in virtue of my history and past desire I benefit more from the visit than my friend does.

It is easy enough to say that that is so because, in virtue of my historical interests and past desire, my experience is different in character. But this move is ad hoc, motivated perhaps by the question-begging assumption that wellbeing is a function of our phenomenal state - which the desire theorist denies. Even if my friend were my duplicate in all respects other than my historical interests and desire to see Hagia Sophia, and was at the time of our visit in exactly the same brain state, neuron by neuron and atom by atom, the case can still be made that going there contributed more significantly to my well-being. Visiting Hagia Sophia benefits both of us because it satisfies our shared desire for aesthetic pleasure, a phenomenal state that both of us achieve. For me, however, it satisfies an additional desire and to that extent I am better off. ${ }^{6}$

I can, of course, imagine an individual who didn't have a standing desire for good feels. Such beings are rare in the state of nature and our intuitions go awry when they turn up in thought experiments. Fictional cases however pump out intuitions. Consider Tolstoy’s Father Sergius, “a handsome prince who everyone predicted would become aide-de-camp to the Emperor Nicholas I and have a brilliant career, [who] left the service, 
broke off his engagement to a beautiful maid of honour, a favourite of the Empress's, gave his small estate to his sister, and retired to a monastery to become a monk." Brilliant, ambitious and well-connected, Sergius, even after leaving the world, is dogged by success, including monkish success as a spiritual adept, and by good feels which he does not desire. Whether we buy Tolstoy's notions about the value of humility and benevolence, it's pretty clear that Sergius' achievements and concomitant good feels don't do a thing for him and, indeed, undermine his wellbeing. What a pity all those good feels are wasted on a monk, we think-we'd sure know what to do with them.

If my duplicate had no standing desire for good feels (or, a fortiori, if she, like Father Sergius, actively wished to avoid them) then I doubt seeing Hagia Sophia would contribute to her wellbeing at all. ${ }^{8}$ As for me, I wanted both to get good feels and to see Hagia Sophia. If each of these desires is satisfied, the satisfaction of each contributes independently to my wellbeing.

Suppose however that I am disappointed on seeing Hagia Sophia. Even knowing all that I do and having seen pictures the experience leaves me cold. Moreover, given the opportunity costs, I am worse off on balance for having gone there: the side-trip to Istanbul cost me the chance to see Venice, which I would have enjoyed much more.

Arguably, however, even if I am disappointed visiting Hagia Sophia contributes to my wellbeing because it is something I wanted to do. The fact that I ended up worse off on net as a consequence of satisfying my desire to see it does not establish that satisfying that desire failed to benefit me at all. It shows only that the visit did not make me as well-off as I had hoped because I did not get the concomitant experience I anticipated and moreover that I was worse off on balance because I did not satisfy my 
desire to see Venice which would have produced a better experience. I would have been even worse off if I had not gotten to either to Istanbul or to Venice.

I reflect, philosophically: "Well, I didn't like Hagia Sophia_but at least I got there."

\section{Changing tastes}

Sometimes, even when we get what we want, having correctly anticipated what it would be like, it does not satisfy us because our tastes have changed by the time we get it. I have always wanted to travel around Europe but by the time I have the money to do it I am too old to enjoy it and would rather stay at home puttering around in my garden. By the time I get the chance to satisfy my desire, doing so would make me on net worse off.

The relatively ephemeral character of desire poses difficulties for any desire theory of wellbeing. ${ }^{9}$ Suppose that at $t_{1}$ I desire $S$, at $t_{2}$ I do not desire $S$ and, shortly thereafter $S$ obtains. Does $S$ contribute to my well-being? If so, when? Not, it seems, at the time that I desire it because then I haven't yet got it; not when I get it because by then I have stopped wanting it. This is suspiciously reminiscent of Epicurus take on the evil of death. When is death an evil for us? Not when we're alive because death is not there; not when we're dead because we are not there.

Sometimes this worry is easy to dismiss because, on closer examination, it turns out that the state I attain is not in fact the state I desired. It may be that $t_{l}$ I desire $S$-at- $t_{--}$ not $S$-at- $t_{2}$-or that at $t_{1}$ I desire that $S$ obtain at a time when I desire $S$ so that $S$ 's obtaining at $t_{2}$ does not satisfy my earlier desire. Such time-bound desires and desires that are contingent on their own persistence do not pose serious difficulties for desire theories. 
Consider Dr. Johnson's predicament. Johnson wanted, and needed, Lord Chesterfield's help when he began work on his Dictionary. After the Dictionary was finished he did not need or want Chesterfield's approval or patronage. There was no time at which he benefited from Chesterfield's support--whether at the beginning of his labors when he wanted but did not get it or at the end when he got it but did not want it. The content of Johnson's desire was time-bound and never, in fact, changed: he did not want Chesterfield's patronage as such — he wanted Chesterfield's help in time to facilitate his project and that was something that he never got. Johnson did not benefit from Chesterfield's belated support because it was not something that he ever wanted. Johnson's predicament therefore should not trouble the desire theorist: there was no time at which he wanted what Chesterfield eventually delivered and hence no time at which he benefited.

In most cases however our desires are not time-bound. As a child I wanted to live in the South but changed my mind long before I ended up spending a year in Tuscaloosa. I did not want to spend some particular part of my life in the South and my desire was not conditional on its own persistence. My desire to live in the South at some time or other was satisfied but it is not clear when, if ever, living in Tuscaloosa contributed to my wellbeing. When did living in Tuscaloosa benefit me? Not as a child because I was not there; not when I lived in Tuscaloosa because then I did not want to be there.

Nevertheless, arguably, there is no compelling reason why we should deny that in virtue of getting what I wanted, even though my desire was long dead by the time it was satisfied, I benefited even though I was not on net better off. On balance, living in Tuscaloosa made me worse off because I incurred substantial opportunity costs. Once my 
desire to live in the South was extinguished and I developed compelling interests in incompatible states of affairs, my past desire did not provide any compelling selfinterested reason for me to move there. Nevertheless, even though I missed out on a lot while living in Tuscaloosa was, on net, worse off than I would have been if I had spent that year somewhere else, I did benefit in virtue of the satisfaction of my past desire.

I reflect, philosophically: well, I didn't want to live in Tuscaloosa when I was there and I didn't like it, but at least I got there.

When it comes to the satisfaction of dead desires in cases like this, the vexed question is not when we benefit but how we weight such desires against live preferences with which they are inconsistent and which, we think, contribute more heavily to wellbeing. ${ }^{10}$ Even assuming that our past and current preferences are equally informed and rationally considered, and equally intense, we do not believe that they should be given equal weight. It does not however follow that they have no weight at all or that we do not benefit when they are satisfied. ${ }^{11}$

Suppose that as a girl I had an all-consuming desire to collect miniature souvenir spoons from all 50 states. My desire for a complete spoon collection is long dead and in fact I now think that collecting spoons reflects adversely on the taste and mental competence of collectors. But I still have a display case in my attic with an almostcomplete collection: only Wyoming is missing. Vacationing near Yellowstone National Park I happen to stop at a roadside stand where I see the spoon that will complete my collection. Intuitively, buying it would contribute to my wellbeing and, arguably, it would make me better off solely in virtue of my past desire. Complete spoon collections are worth very little so it will not be worth my while to advertise it on eBay; my spoon 
collection has no sentimental value for me and I have no interest in passing it down as an heirloom; moreover, I do not want to be the sort of person that has a complete collection of souvenir spoons. It is only in virtue of my long-dead desire to assemble such a collection that completing the set makes my life, admittedly in a very minor way, better. ${ }^{12}$

Cases like this are rare: current desires normally trump past preferences when it comes to deciding what we shall do. We weigh current desires more heavily than past ones because we, in most cases quite rationally, discount the future: a bird in the hand is worth two in the bush. Regarding my past desires I consider how satisfying them now would have looked from my past perspective and in most cases, given a reasonable discount rate and figuring in my current preferences, striving to satisfy them is not worth it.

Ten years ago I wanted to visit Vienna. Now that I have the opportunity to see Europe, I no longer want to go: among other things, I discovered since then that in spite of passing the departmental language exam in grad school I cannot understand a word of German. I would much rather go to France where my best friend's sister has a horse farm and the language is less inflected.

Even from my earlier perspective, given my discount rate, a trip to Vienna 10 years in the future might not have been worth very much, particularly if my desire was informed by a realistic assessment of my future linguistic capabilities. Satisfying that desire now will benefit me-but the benefits will be minimal and, in light of the opportunity costs, I will be on net worse off. In general, we weigh current preferences more heavily than past desires, and give more consideration to recently past desires than 
to remote ones because in assessing what their satisfaction will do for us we adopt the perspective of the time at which they were current and discount the future.

Sometimes however, even discounting the future, those past preferences carry enough weight to trump current preferences. As a child building my spoon collection was a very big deal and I would have been ecstatic had I learnt that I would eventually get that last spoon. Even at fairly steep discount rates the future satisfaction of such desires weighs heavily. If I run across that last spoon fortuitously and can buy it for pocket change, in spite of the fact that I no longer want to complete my collection, I am still better off getting it.

It's a crying shame that I didn't find that spoon sooner, when I would have enjoyed getting it. According to the desire theory, however, while pleasant experiences, including the experience of desire satisfaction, benefit us because we want them, they are not the only states of affairs that benefit us. Any state of affairs that we desire benefits us, even if it obtains after we have ceased to desire it and indeed, as I shall argue, even if it only obtains after our deaths when we are beyond all desire and the experience of its satisfaction.

\section{Retroactive prudential improvement}

The intuition that posthumous states of affairs can harm or benefit individuals is fragile and far from universal:

Wise men also die and perish together, as well as the ignorant and foolish, and leave their riches for other. 
And yet they think that their houses shall continue forever, and that their dwelling-places shall endure from one generation to another; and call the lands after their own names.

Nevertheless, man being in honour abideth not, seeing he may be compared unto the beasts that perish...

For he shall carry nothing away with him when he dieth, neither shall his pomp follow him.

Psalms 49:10-12,17

The desire theorist however is committed to the view that states of affairs that do not enter into our experience, including posthumous states of affairs, may in and of themselves, benefit us. The benefits that come from posthumous desire satisfaction however pose special problems: it is not just that there is no time at which we shall be in a position to learn that we have benefited from posthumous desire satisfaction - it is not clear that there is any time at which we benefit.

Posthumous benefits, and harms, pose a trilemma for the desire theorist. If we benefit from the posthumous satisfaction of desires then either (1) we benefit timelessly so that, though the satisfaction of our desires does not produce any "momentary wellbeing," our lives overall go better or (2) we benefit at some time during our lives, prior to the satisfaction of our desires or (3) we benefit posthumously, presumably at the time that our desires are satisfied. While none of these accounts poses serious logical difficulties I argue that in a range of cases it is most plausible to suggest that the momentary wellbeing that comes from satisfying our desires occurs posthumously. After dealing with each of these possibilities in turn I shall grasp the third horn of the trilemma. 


\subsection{The benefit we get from the posthumous satisfaction of some desires is momentary}

Some of our desires are such that their satisfaction does not produce any momentary wellbeing: these desires are global and there is no moment, either during our lives or afterwards at which they are satisfied. Among the goods we desire are what Broome (2004) has called "pattern goods": we want our lives, or at least some stretches of our lives, to go a certain way or exemplify a particular narrative. Velleman (1991) for example suggests that most people prefer "uphill" to "downhill" lives-even given the same sum of momentary wellbeing through their lives in toto they would choose lives that improve over time, preferably through their own efforts. ${ }^{13}$ When it comes to such desires, because of the nature of their objects, there is no time during our lifetimes at which they are satisfied and no moment at which we benefit even though, in virtue of being satisfied we should say our lives in toto go better.

The satisfaction of other desires however yields momentary wellbeing: I wanted my paper to be accepted and when the decision was made to publish it I benefited even though at the time of that decision I did not experience felt satisfaction or acquire any relevant non-Cambridge properties: I became better off when the decision was made in some remote conclave long before I received the letter of acceptance and experienced the pleasure of achievement. If my paper had been accepted posthumously I would have benefited in virtue of that desire also-but when?

If I had had a global desire to publish a certain body of work during my lifetime I should perhaps have benefited timelessly from the publication of my paper. But that is not what I wanted: to the extent that I have any preferences regarding my life in toto I just want to get what I want (whatever it happens to be) on as many occasions as possible. I 
have no interest having my life exemplify any particular narrative or in leaving an intellectual legacy: I just like writing papers and when I write a paper I want to get it published. Conjuring up global desires to be timelessly satisfied here is an ad hoc attempt to circumvent the question of when I benefit from posthumous desire satisfaction.

So we cannot escape by grasping the first horn of the trilemma: some posthumously satisfied desires are not global - their satisfaction is momentary and we cannot evade the question of when we benefit by assimilating these cases to those in which we either benefit timelessly, throughout our whole lives or non-momentarily through some stretch of our lives.

\subsection{There is no time during an individual's lifetime to which the benefit of posthumous desire satisfaction should be pinned}

Assigning any time during my life to the apparently momentary wellbeing that comes from posthumous desire satisfaction is fishy. Feinberg (1984) for example suggests that an individual is harmed or benefited by a posthumous event that thwarts or satisfies his antemortem desire "at some point well before his death when the person had invested so much in some postdated outcome that it became one of his interests. ${ }^{.14}$ This is odd. Suppose I write a paper that is only accepted for publication after I am dead. I put my heart into writing that paper and invest so much in the postdated outcome of my efforts that getting it published becomes one of my interests long before it is accepted. Shall we say that even if I had lived to see my paper accepted I would have benefited at the same time, when I had invested so much in getting it published that it became one of my interests or shall we say that if I had lived I would have benefited only have benefited later, when the paper was accepted? Does death intervening between the time publication 
becomes one of my interests and the time my paper is accepted make a difference to when I benefit or not?

Suppose death does not make a difference and whether we live or die we benefit from a postdated outcome when we have invested so much in it that it becomes one of our interests. On this supposition, where $x$ desires $S$, and at some time, $t_{l}$ has invested so much in working to bring it about that it is then in his interest that $S$ obtain it is at $t_{l}$, that $x$ benefits from $S$ 's obtaining in the future whether he's around or not.

But, suppose $S$ obtains at a time $t_{2}$ during $x$ 's lifetime. When $S$ came about something good happened to $x$ : the project in which he'd invested came to fruition. Moreover, he would have benefited at $t_{2}$ even if he did not find out about it then. In a remote gulag, $x$ does not learn that the Revolution has succeeded: $t_{2}$ is just another day in the salt mines for him even though, unbeknownst to him, it's the best day of his life: he has been vindicated and everything he dreamed of, worked for and sacrificed for has come to pass. We would never say in circumstances like this: "Pity $x$ invested so much in $S$ at $t_{1}$ that it became in his interest back then, so that he got that shot of momentary wellbeing at $t_{l}$ rather than $t_{2}$ : if he'd saved that wellbeing for later he would have had an uphill life." Intuitively, $x$ benefits from $S$ at $t_{2}$. If we want to remain faithful to that compelling intuition we shall have to say that where a person's interest is satisfied during his lifetime, he benefits when it is satisfied. So if we want to take Feinberg's suggestion about when we benefit from posthumous outcomes we will have to say that death does make a difference to when we benefit.

Now suppose that when an individual's interest in some state of affairs, $S$, is satisfied posthumously he benefits "at some point well before his death," either when he 
comes to desire $S$ or, as Feinberg suggests, when he has invested so much in $S$ that it becomes one of his interests, but that if he survives he only benefits later, when $S$ obtains. Then we have to explain why premortem desire satisfaction or interest fulfillment benefits people when it happens but posthumous desire satisfaction or interest fulfillment benefits them earlier on, when they acquire the relevant desires or interests. There are two lines we can take:

One possibility is that, while in normal cases, where a person's desires or interests are satisfied during his lifetime he benefits when they are satisfied, our folk psychological concepts of desire, wellbeing and the like do not give us any inkling about what to say in abnormal cases when they are satisfied posthumously. On this account, in such abnormal cases we should either throw up our hands and say there is no answer or pick some premortem time and, by convention, decide that it will count as the time that the individual involved benefits.

This response is reminiscent of concerns some philosophers have about the use of puzzle cases to elicit "our" criterion for personal identity. We've never had to deal with fission or fusion, brain-zaps, Startreck machines or brains in vats so it may be that our concept of a person does not convey any identity criteria to deal with these cases. There is however an important difference between worries about the more bizarre puzzle cases of personal identity and the cases under consideration: posthumous desire satisfaction is not "abnormal." It happens all the time. So even if it is plausible to suggest that our concept of a person does not give us any guidance when it comes to elaborate sciencefictional scenarios that do not happen and likely cannot happen in the order of nature, it is far less plausible to take this tack when it comes to posthumous desire satisfaction. 
The other option, again inspired by the literature on personal identity, is to adopt a best candidate account for selecting the time at which a person benefits from the satisfaction of his desires or interests. According to such accounts there are some concepts that convey diverse criteria for application, some of which dominate others. So, while our dominant criterion for identifying artifacts through time is spatio-temporal continuity, where that fails we fall back to a secondary criterion: sameness of parts. In the most familiar case, the Ship of Theseus survives as the Continuously Repaired Ship, a vessel that is spatio-temporally continuous with the original even though after decades of reconstruction it does not have any of the same parts. If however the Continuously Repaired Ship hadn't survived, we should identify the Plank Hoarders Ship, composed of all and only the planks cast off from the Ship of Theseus during its ongoing refurbishment, as the Ship of Theseus because, absent the Continuously Repaired Ship, it is the best candidate.

The problem of posthumous desire satisfaction lends itself to this treatment because, according to the desire theory, there are two conditions that have to be met for an individual's wellbeing to increase - his desiring $S$ and $S$ 's obtaining — and these conditions may be satisfied at different times. So maybe we should say that while the dominant criterion for dating the momentary wellbeing that accrues to an individual is the time of satisfaction, where this fails, we fall back to a secondary criterion: the time at of desire or the time at which an individual has invested so much in an outcome that it becomes one of his interests. Assuming that individuals cannot benefit posthumously we say that if $x$ survives to $t_{2}$, when $S$ obtains he benefits at $t_{2}$; if he does not survive then the best candidate time is $t_{1}$ so that is when he benefits. 
This is a peculiar counterfactual but best candidate theories always throw up peculiar counterfactuals. In the case of the Ship of Theseus, given the best candidate treatment, where only the Plank-Hoarder's Ship survives we say, "Good thing the Continuously Repaired Ship got zapped because if it hadn't this ship wouldn't be the Ship of Theseus," and if both ships survive we say of the Plank-Hoarder's ship, "Good thing the Continuously Repaired ship is up and running because if it hadn't survived, this ship wouldn't exist." Best candidate theories are always fishy.

The best candidate solution to the problem of posthumous desire satisfaction is however even fishier than usual for best candidate theories because there is no reason to think that the time an individual acquires a desire or the time at which a desire becomes in interest is even a second best candidate for the time of benefit: they are not candidates at all. When it comes to the Ship of Theseus there is some motivation for hoarding planks: a prudent plank-hoarder with an interest in historical preservation may want to keep an extra ship as a back-up: "If anything happens to that ship out on the high seas, at least we've still got this one." But there is no comparable motivation for forming desires or investing to bring it about that some state of affairs is in ones interest.

Suppose I know that I have only a month to live and that I will not survive to see a whole raft of my desires satisfied. I will not regard my current desires or interests as back-ups. I am not going to take comfort in the thought that because I will not live to see these desires satisfied they now contribute to my wellbeing. I am certainly not going to try to work up desires for more states of affairs that will only obtain after my death or invest more in postdated outcomes to the extent that they become interests for me in order to secure additional wellbeing for myself now. If anything, what I will do is divest 
myself of desires for future states, cash out my investments in outcomes that will only obtain after my death and abandon long-term projects. Principled individuals with moral agendas may behave differently but insofar as I am after my own wellbeing I will seize the day.

The best candidate solution is not logically incoherent. There is no general problem with accounts according to which later events bring about earlier ones so long as we recognize that not all bringing-about is causal: grades are changed retroactively, marriages are annulled and medals are awarded posthumously. The problem is that these accounts yield counterintuitive results because, whichever way you cut it, if there is any time at which an individual benefits from the satisfaction of his desires it is the time at which they are satisfied. So, assuming that there is a time at which individuals benefit from posthumous desire satisfaction, it must be after their deaths. And, I shall argue, that is not as crazy as it sounds.

\subsection{Individuals benefit from the posthumous satisfaction of their desires posthumously}

When does a state of affairs benefit us? Understood in one way, it benefits us at the time that we commence being better off in virtue of it; understood in another way, it benefits us when it makes us better off. Posthumous states that satisfy our desires benefit us in the latter sense after our deaths - and that, I argue, is the relevant sense when we want to know about "momentary wellbeing."

In general, if we ask when an object, $x$, comes to have a property, $\mathrm{P}$, there are two events we could be asking about — the event which brought it about that $x$ has $\mathrm{P}$ and the start of the stretch of $x$ 's history during which it has $\mathrm{P}$. "Becoming $\mathrm{P}$ " is ambiguous between being made $P$ and commencing to be $P$, events which may be, but need not be, 
simultaneous. I became a mother at the time that I gave birth to my first child. This event made me a mother and coincided with the commencement of my motherhood. Sometimes however there is a temporal gap: I was hired for my present position in April but started work in September. The event that made me a member of the faculty occurred in April, so if the question is one of when the event that, eventually, conferred that status on me occurred, it is in April: the stretch of my life during which I was a member of the USD philosophy department did not commence until September. My contract gave September 1 as its starting date.

When an event brings it about that an object commences to have a property in this way it does not cause the object to acquire that property. The departmental hiring decision conferred a status on me: it entitled me to a salary, office and benefits starting the following September. It did not cause me to get the paycheck, the Kaiser card or the office key. Causation requires a mechanism and intervening events, but the conferring of entitlements and bringing about of other Cambridge changes can leap both spatial and temporal gaps, as was the case when the hiring decision in April brought it about that I became a member of the USD philosophy department in September. Moreover, while causation goes only goes one way, from earlier to later events, the bringing about of Cambridge changes goes every which way. Grades are changed retrospectively and awards are conferred posthumously: the Congressional Medal of Honor is almost always conferred posthumously since just about everyone foolhardy enough to do what it takes to get it, is killed in the process. When a grade or award is conferred ex post facto the event that makes an individual have a property postdates his commencing to have that property. 
In typical cases, when an individual's desire for some state, $S$, is satisfied during his lifetime, he commences to be better off at the same time that $S$ makes him better off, viz. the time at which $S$ comes about. At $t_{1}, x$ wanted $S$; at $t_{2}$ he got it. At $t_{2}$ the start of $S$ 's obtaining made $x$ better off. $T_{2}$ also marks a boundary between a stretch of $x$ 's history when he was less well off and a stretch of his history when he was better off: it is the moment he commenced being better off.

Sometimes however the objects of our desires are necessarily non-momentary. I want the conference that I'm planning to go well, with good papers, good discussion lots of schmoozing. I will benefit if it goes well but there is no moment at which the satisfaction of that desire makes me better off. The start of the conference doesn't make me better off; the end of the conference doesn't make me better off - if anything it makes me worse off because that is when the fun comes to an end; and no momentary event in between makes me better off. I commenced being better off at the start of the conference but what happened then is not "momentary wellbeing" like the slug of momentary wellbeing I got when my paper was accepted or when, after years of yearning, I finally got a dog. This is characteristic of the wellbeing we achieve when we satisfy our desires for "pattern goods" and suggests that the distinction between the non-momentary wellbeing we achieve when our lives, or some stretch of our lives, go well and momentary wellbeing concerns the character of the state that makes us better off rather than the commencement of our elevated level of wellbeing. Sometimes, indeed, when the objects of our desires are global, when we want our lives in toto to go a certain way, there is no time during our lives when we commence being better off. We are, nevertheless, 
better off for satisfying such desires - and what makes us better off is the totality our lives.

So it is not implausible to suggest that when we ask for the time that a person benefits from the satisfaction of his desires, we are asking about the time- whether a moment or a stretch of time - at which the object of his desire makes him better off rather the time during his life, if any, when he commences to be better off. If we take this suggestion, the problem of posthumously satisfied desires has an easy, intuitive solution: an individual benefits from posthumously satisfied desires when, after his death, the states he desires come to be. If my paper is accepted for publication after my death, the posthumous time of the decision is the moment at which I benefit.

\section{THE PROBLEM OF EX ANTE DESIRE SOLVED}

I have argued that the temporal gap between our desires and the states of affairs that satisfy them does not pose any insurmountable difficulties for the desire theory. We benefit from the satisfaction of our desires when the states of affairs we desire make us better off, even if by then our desires are dead, and even if we ourselves are dead. Epicurus' argument is a sophism: we don't have to be "there" to be harmed by death. But we may take some consolation in the fact that we don't have to be "there" to be benefited by posthumous desire satisfaction either.

\section{BIBLIOGRAPHY}

Brandt, R. B., 1984 [1979]. A Theory of The Good and The Right, Oxford: Oxford University Press.

Broome, J. 2004. Weighing Lives. Oxford: Oxford University Press. 
Bykvist, K. 2005. "What is Wrong with Past Preferences?" "What is Wrong with Past Preferences?" at http://213.80.36.53/temp/filosofen3/files/prodok8.pdf (unpublished)

Feinberg, J. 1984. Harm to Others. Oxford: Oxford University Press.

Griffin, J. 1986. Well-Being: Its Meaning, Measurement, and Moral Importance. Oxford: Oxford University Press.

Grover, D., 1989, “Posthumous harm”, Philosophical Quarterly 39: 334 - 353.

Heathwood, C. 2006. "Desire Satisfactionism and Hedonism.” Philosophical Studies.

Keller, S. 2004. "Welfare and the Achievement of Goals." Philosophical Studies 121:2741.

Luper, S. 2004. “Posthumous Harm.” American Philosophical Quarterly 41:63-72.

Luper, S. forthcoming. "Past Desires and the Dead." Philosophical Studies.

Murphy, M. 1999. “The Simple Desire-Fulvillment Theory.” Nous 33:247-272.

Parfit, D., 1984. Reasons and Persons. Oxford: Oxford University Press.

Pitcher, G. 1984. “The Misfortunes of the Dead.” American Philosophical Quarterly 21:183-188.

Portman, D. 2005. "Welfare and Posthumous Harm.” (unpublished)

Rosati, C. S. 1995. "Person, Perspectives, and Full Information Accounts of the Good," Ethics 105:296-325

Sumner, L. W. 1996. Welfare, Happiness and Ethics. Oxford: Oxford University Press. Velleman, J. D. 1991. “Well-Being and Time.” Pacific Philosophical Quarterly 72:4877.

Vorobej, M. 1998. "Past Desires.” Philosophical Studies 90:305-318. 
${ }^{11}$ I am grateful to participants at the session of the Inland Northwest Philosophy Conference on Time and Identity where an earlier version of this paper was read for their comments and most particularly to the anonymous referee for this volume.

${ }^{2}$ Sumner, 1996

${ }^{3}$ We are, all of us, prone to dynamic inconsistency: all of us have lost desires we used to have and are, in many cases are indifferent about their satisfaction. According to Derek Parfit (1984), from the standpoint of our self-interest we have no reason to care whether our PI desires are fulfilled, and no reason to fulfill them were the opportunity to arise. Intuitions about this matter however differ: Kryster Bykvist (2005) is maintains that “[w]hen past preferences are replaced by new ones, it seems absurd to say that we ought to respect the preferences we once had." Other writers however suggest even if present desires outweigh or trump past desires, ceteris paribus, the satisfaction of past desires, in particular those which we have not intentionally repudiated, contributes to wellbeing. See, e.g. Luper (2006).

${ }^{4}$ See, e.g. Pitcher (1984) and Feinberg (1984) on posthumous harms.

${ }^{5}$ Sumner 1996, 132

${ }^{6}$ Simon Keller (2004) argues that the investment we make in working to achieve goals contributes to their benefit for us once we achieve them and that indeed seems to figure in cases like this one. I have been accumulating frequent flyer miles for years to get that trip to Istanbul. But I do not think that it is required to back our intuition that Hagia Sophia does more for me than for my duplicate. Even if I have not made any effort to achieve my goal I may have the standing desire that my life go a certain way as regards experiences, 
e.g. to assemble a collection of experiences of the worlds most significant works of architecture as part of my life history.

${ }^{7}$ Tolstoy, L. N. "Father Sergius.” Library of Christian Classics Ethereal Library. http://www.ccel.org/ccel/tolstoy/sergius.ii.html

${ }^{8}$ If this intuition seems off, consider a comparable situation where bad feels are involved. Patients given some drugs report that they still feel pain but no longer mind it--the sensation is the same but the aversion is gone. It is not implausible to suggest that absent the aversion the sensation does not diminish the subject's wellbeing. It is moot whether, in the absence of aversion we should characterize a sensation as "pain" and, by the same token whether we should regard any unwanted feels, regardless of their qualitative character, as good. Arguably, however, in both cases it is not the phenomenal character of the experience that contributes to wellbeing or undermines it but the desire or aversion. ${ }^{9}$ See, e.g. Steven Luper, "Past Desires and the Dead," forthcoming in Philosophical Studies for a discussion of the "lost desire thesis," the doctrine that we have no selfinterested reason to care whether past desires about which we are currently indifferent are fulfilled.

${ }^{10}$ For an extended discussion see, e.g. Krister Bykvist 2005.

${ }^{11}$ Vorobej (1998) suggests that philosophers may be inclined to deny the normative power of past desires because they assume that if past desires count at all they must be given the same weight as other desires and so overlook "non-egalitarian temporal neutrality theses." Parfit, he suggests, concludes illegitimately from the intuitions suggesting that past desires ought not to be given the same weight as current ones to the conclusion that they ought to receive no weight at all. 
${ }^{12}$ Brandt (1979: 249-250) wonders about the following case. Your six-year-old son has a present desire to celebrate his fiftieth birthday by taking a roller-coaster ride. You know that by his fiftieth birthday that desire will be long dead. Reflecting on this case, Bykvist suggests plausibly that it seems wrong to count this preference: "why should this preference be respected when your son will unavoidably lose all interest in rollercoasting? If you satisfy this preference, then he will end up later doing what he then does not want to do."

This is not a particularly compelling example because it is easy enough to write off your son's desires as uninformed or irrational insofar as he likely believes that he will enjoy a roller coaster ride on his fiftieth birthday as much as he enjoyed it on his sixth. It does not in any case follow that there are no cases in which earlier preferences trump current ones.

${ }^{13}$ Velleman (1991) argues compellingly that overall wellbeing is not a function of momentary episodes of wellbeing during a person's lifetime: some of the goods that make our lives go well are what Broome (2004) calls "pattern goods." Some of us, at least, want our lives to exhibit a certain narrative structure, e.g. as Velleman notes even were the same amount of overall utility is involved, we prefer that our lives go better over time than that they start off well and go worse.

${ }^{14}$ Fineberg, 1984, 921. 